\title{
Influence of rotational speed on the electrical and mechanical properties of the friction stir spot welded aluminium alloy sheets
}

\author{
Danka Labus Zlatanovic ${ }^{1,2}$. Jean Pierre Bergmann ${ }^{1} \cdot$ Sebastian Balos ${ }^{2} \cdot$ Michael Gräzel $^{1} \cdot$ Dragan Pejic $^{3}$. \\ Platon Sovilj ${ }^{3}$ Saurav Goel ${ }^{4,5}$
}

Received: 13 August 2021 / Accepted: 1 February 2022 / Published online: 10 February 2022

(c) The Author(s) 2022

\begin{abstract}
An efficient and productive joining technique to weld aluminium has become a priority challenge for promoting the use of aluminium in the electrical industry. One of the challenges is to obtain welds with superior mechanical properties with the consistent quality of weld surface as well as low electrical resistance. In this paper, the influence of rotational speed during the friction stir spot welding of AA 5754-H111 was studied to analyse the mechanical and electrical properties of the welds. The results from two rotational speeds $(1000 \mathrm{rpm}$ and $4500 \mathrm{rpm})$ are presented and compared to the base material. It was observed that the samples welded at $1000 \mathrm{rpm}$ showed a higher average shear failure load $(\sim 1.1 \mathrm{kN})$ compared to the samples welded at $4500 \mathrm{rpm}(\sim 0.94 \mathrm{kN})$. The microhardness of the samples welded at $1000 \mathrm{rpm}$ was higher than that of the base material, while the microhardness of samples welded at $4500 \mathrm{rpm}$ was lower. It was also found that the friction welded sheets, regardless of the rotational speed used, showed increased electrical resistance compared to the base material, albeit this increase for the samples welded at $1000 \mathrm{rpm}$ was about $42 \%$, compared to samples welded at $4500 \mathrm{rpm}$ where this increase was just $14 \%$.
\end{abstract}

Keywords Friction stir spot welding $\cdot$ Aluminium alloy $\cdot$ Rotational speed $\cdot$ Electrical resistance

\section{Introduction}

The use of lightweight alloys in the automotive and aerospace industries is significantly being promoted, thanks to the drive to the decarbonised economy [1]. The concerns

Recommended for publication by Commission IX-Behaviour of Metals Subjected to Welding

Danka Labus Zlatanovic

danka.labus-zlatanovic@tu-ilmenau.de

1 Department of Production Technology, Technische Universität Ilmenau, 98693 Ilmenau, Germany

2 Department of Production Engineering, Faculty of Technical Science, University of Novi Sad, 21000 Novi Sad, Serbia

3 Department of Power, Electronic and Telecommunication Engineering, Faculty of Technical Science, University of Novi Sad, 21000 Novi Sad, Serbia

4 School of Engineering, London South Bank University, London SE1 OAA, UK

5 University of Petroleum and Energy Studies, Dehradun 248007, India related to climate change are influencing all areas of engineering, and currently, in the automotive sector, a key driver is to substitute copper with aluminium to save weight and material costs, particularly for battery-operated vehicles where a wide range of terminals, connectors, and wires will form significant weight of the vehicle. While an effective reduction of energy consumption through efficient manufacturing is desirable, there is also a fear about the supply risk of the critical raw material and the price fluctuations associated with it. Therefore, the development of improved technologies for joining aluminium and its alloys, with acceptable weld characteristics and minimal energy consumption, is desired [2, 3]. However, joining of aluminium and its alloys, especially with solid-state welding techniques, is a challenging task due to a persistent and chemically stable aluminium oxide layer naturally existing on the top and at the surface of the sheets prior to the welding due to the reaction between nascent aluminium and atmospheric oxygen [4].

Friction stir spot welding (FSSW) technology offers various advantages over other joining technologies such as high mechanical properties, small or no distortion of welds, low energy consumption, and no consumable or shielding gas 
involvement [5, 6]. Moreover, it offers a defect-free microstructure of the weld zone, and it is especially convenient for welding aluminium alloys. The basic concept of FSSW is relatively simple. A rotating tool with a specially designed probe and shoulder is allowed to penetrate the upper sheet in the overlapping area until a certain plunge depth is reached. The process lasts until the sheets join to each other, and at this point, the rotating tool retracts which leaves a keyhole behind. The keyhole affects the surface and weld quality of the joints, especially during the welding of thin aluminium sheets [7].

Consequently, a probe-less (or pin-less) tool friction stir spot welding (PLT-FSSW) process was proposed to overcome the drawbacks of keyhole [8, 9]. During PLT-FSSW, the deformation induced by the tool results in stretch-induced strain in the sheets causing fragmentation of the brittle oxide layer on top of the sheets at the weld faying interface (WFI). As these fragments remain entrapped within WFI, they tend to impede the homogeneity in the diffusion bonding resulting in nonuniform weld joint quality and becoming nucleation hotspots for joint fracture [10].

Sato et al. [11] was the first who analysed the details of WFI in the friction stir welded aluminium butt weld (AA 1050). The effect of the oxide layer on the mechanical properties of the weld was systematically examined to clarify the identity of the kissing-bond effect in FSW joints. However, during FSSW, this effect is different because it is a lap joining method and in the present literature, WFI of FSSW joints often alludes to as bonding ligaments (BL). It is considered to be an initial place where delamination during shear tests occurs [12]. BLs have been widely studied at the macro and micro scales. Mostly the influence of their length, shape, and distribution on the shear strength of the welds has been analysed. Sarkar et al. [12] used tracer materials as inserts to study material flow and bonding ligament formation during FSSW of 1.6-mm-thick DP590 steel. It was found that BLs were created by intermixing of material of two overlapping sheets. With increasing rotational speed, ligament width increases. Tier et al. [13] studied the influence of rotational speed on the length of BL during refill friction stir spot welding. They observed that reduction of rotational speed from 1900 to $900 \mathrm{rpm}$ increases the length of BL and shear stress. Li et al. [14] studied the effects of rotational speed on the weld quality during RFSSW of 2A12T4 aluminium alloy. The tensile-shear properties of welds were found to be dependent on hook geometry, distribution of bonding ligament, and hardness. With increasing rotational speed from 900 to $1300 \mathrm{rpm}$, the bonding ligaments of the weld periphery were more dispersed, and the hardness of the stir zone was observed to decrease. Recently Labus Zlatanovic et al. [10] analysed the origins of delamination in multiple sheets of AA 5754 aluminium alloy joined by FSSW. Detailed microscopic characterisation revealed the complex interfacial layer formed because of stress-assisted metallurgical transformation at the intersection of WFI. In this study, the influence of WFI on weld quality was studied only via a small punch test which showed that the highest overall weld was achieved when FSSW was carried at a lower rpm (1000 rpm).

An investigation into the electrical properties together with the mechanical properties will answer the key question asked by this paper, "how does the rotational speed influence the electrical resistance of the welded joint as a function of changed microstructure"? This research question formed the core of the investigation pursued in this paper, and as a by-product, several other salient features were also investigated, which are focussed primarily on the changes in the local microstructure of the weld interface. Consequently, this paper reports the influence of rotational speed on the thickness of WFI and its metallurgical composition.

\section{Research methodology and experimentation}

\subsection{Base material}

The work began by procuring AA 5754-H111 aluminium alloy sheets with its quotes chemical composition and mechanical properties shown in Tables 1 and 2, respectively. Four sheets having $0.3 \mathrm{~mm}$ thickness were cut in sizes of $45 \times 110 \mathrm{~mm}$.

\subsection{Friction stir spot welding process}

The process of FSSW studied in this paper relied on using a force-controlled welding machine EJOWELD C50R FSSW (EJOT GmbH \& Co. KG Geschäftsbereich EJOWELD, Tambach-Dietharz, Germany). The maximum rotational

Table 2 Mechanical properties of AA 5754-H111 aluminum alloy quoted by the material supplier

\begin{tabular}{llll}
\hline Material & $\begin{array}{l}\text { Minimum yield } \\
\text { strength (MPa) }\end{array}$ & $\begin{array}{l}\text { Tensile strength } \\
(\mathrm{MPa})\end{array}$ & $\begin{array}{l}\text { Elongation - } \\
\text { A50 (\%) }\end{array}$ \\
\hline AA 5754-H111 & 80 & $190-240$ & 10 \\
\hline
\end{tabular}

Table 1 Chemical composition of AA 5754-H111 aluminium alloy quoted by the material supplier

\begin{tabular}{llllllllll}
\hline Element & $\mathrm{Si}$ & $\mathrm{Fe}$ & $\mathrm{Cu}$ & $\mathrm{Mn}$ & $\mathrm{Mg}$ & $\mathrm{Cr}$ & $\mathrm{Zn}$ & $\mathrm{Ti}$ & $\mathrm{Al}$ \\
\hline wt. $(\%)$ & 0.40 & 0.40 & 0.10 & 0.50 & $2.6-3.6$ & 0.30 & 0.20 & 0.15 & bal \\
\hline
\end{tabular}


speed in this machine can go up to $9000 \mathrm{rpm}$, with a maximal axial load of $8 \mathrm{kN}$ and a dwell time of $5 \mathrm{~s}$. A detailed description of the process setup has been provided elsewhere [15]. The tool used in this work (see Fig. 1) was made from H13 (X40CrMo51) hot-work steel. The tool had a convex contact surface which provides a gradual increase of the pressure providing FSSW of ultrathin sheets without tearing the sheet with tool edge. Consequently, four ultrathin aluminium sheets were lap joined with this convex probeless tool.

The experimental parameters used in this study were in accordance with the previous study [10]. Two samples were welded at an axial load of $4 \mathrm{kN}$, the penetration depth of $0.25 \mathrm{~mm}$, and two representative rotational speeds of $1000 \mathrm{rpm}$ and $4500 \mathrm{rpm}$.

\subsection{Macro- and microstructural characterization}

The two samples processed by FSSW were prepared for metallographic examination. The samples were ground with abrasive paper (grit 360 to 2500) and polished with diamond suspension ( 6 and $3 \mu \mathrm{m})$. The final step was fine polishing with colloidal silica with an average particle size of $0.05 \mu \mathrm{m}$ (OP-S). After polishing, electrolytic etching was performed with Barker's etching agent ( $5 \mathrm{~mL} \mathrm{HBF} 4+200 \mathrm{~mL} \mathrm{H}_{2} \mathrm{O}$ ) using a Struers LectroPol-5 device (40 V, 2 min). The crosssection of the samples was analysed by Zeiss, AxioScope A1 light microscope with AxioCam ICc3. Cross-polarised light under sensitive tint was used for revealing different colours of the grains having different orientations.
The WFI on both samples was analysed with a $200 \mathrm{kV}$ transmission electron microscope (TEM, Tecnai Osiris, FEI) additionally equipped with a scanning unit (STEM) including a high-angle annular dark-field (HAADF, Fischione Co.) detector and energy dispersive X-ray spectrometer (EDX, Super-X system with 4 Bruker silicon drift detectors, Thermo Fisher Co.).

\subsection{Electrical properties}

The electric circuit used for measuring the electric resistance in samples welded at 1000 and $4500 \mathrm{rpm}$ and base material is shown in Fig. 2. The calculation of specific electric resistance was done by using Ohm's law [16]:

$R=\frac{V}{I}=\rho \cdot \frac{l}{w \cdot h} \rightarrow \rho=\frac{V}{I} \cdot \frac{w \cdot h}{l}$

where $R$ is electrical resistance $(\Omega)$; $V$ is voltage (here present at $2 \mathrm{~V}$ ), $I$ is the measured current (A), $l$ is the length between the two contacts (set at $8 \mathrm{~mm}$ ), and $w$ and $h$ are widths and height of the cross-section measured individually for each specimen by a micrometer (mm).

A Time Electronics 5025 generator was used to supply 2 A current (shown by the red line in the circuit in Fig. 2). The voltage was measured at the pre-set distance of $8 \mathrm{~mm}$ (crosssection of the red circle in Fig. 2a), by using the FLUKE 8846A device (Fig. 2b). This is the distance which signifies start of the weld (stir) zone (red circle). This measurement scheme provided specific measurements in the stir zone. In all samples, the measurements were performed 12 times at
Fig. 1 Schematic of tool used for friction stir spot welding [10]
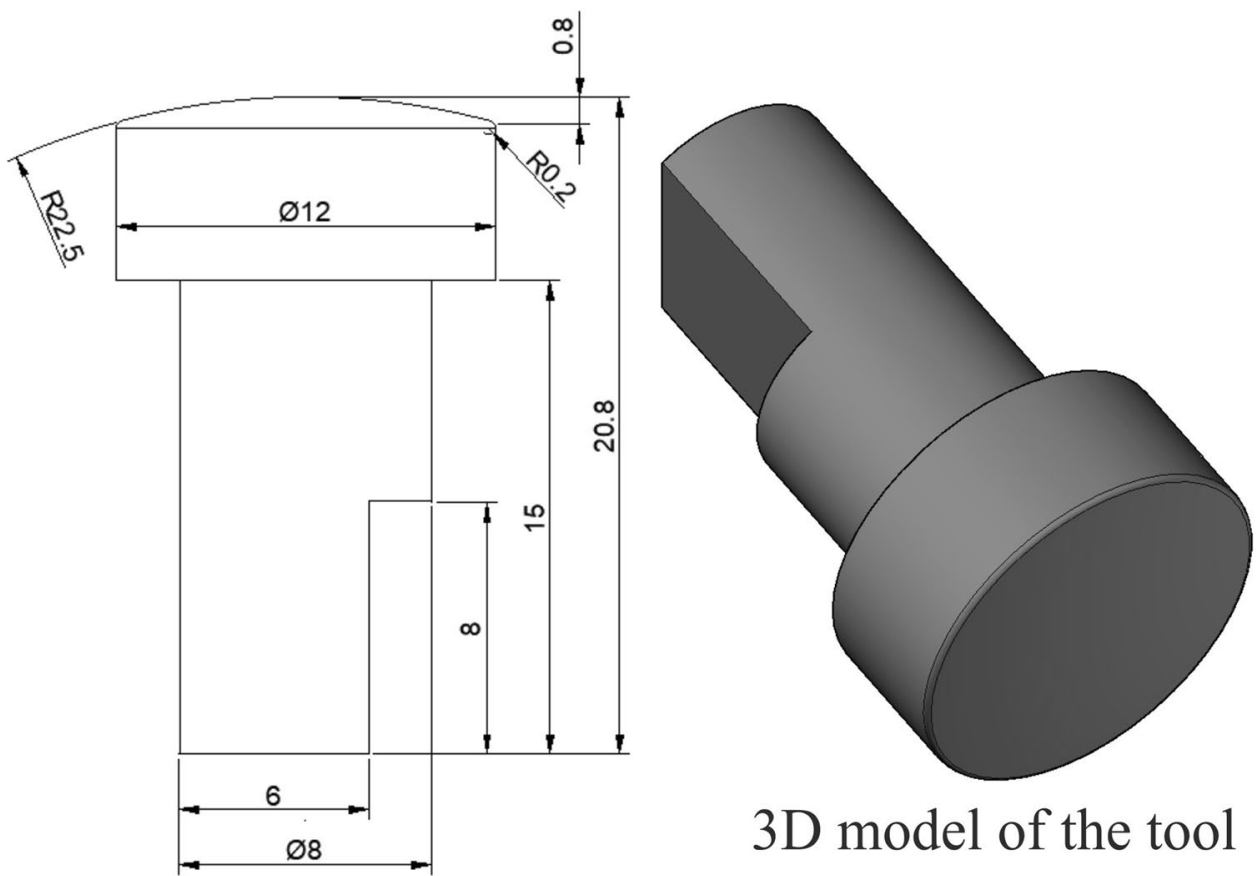

3D model of the tool 

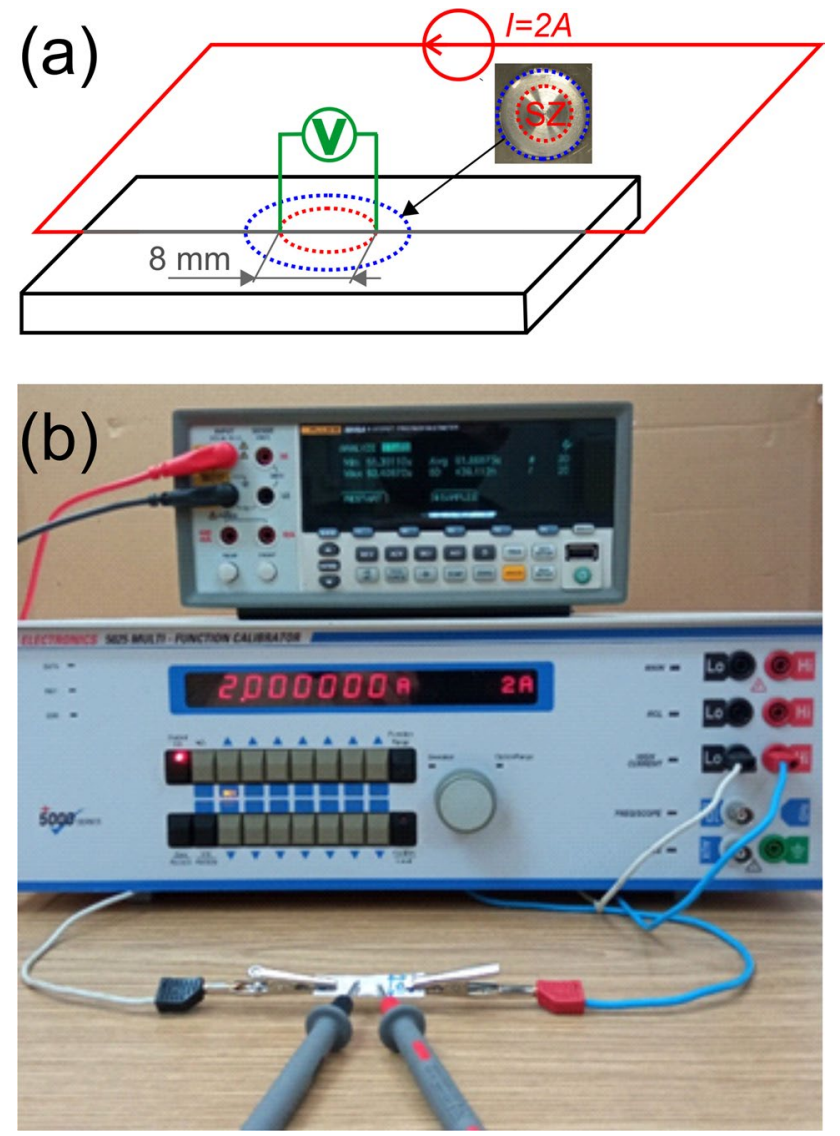

Fig. 2 a Schematic of the electrical resistance measurement setup; b generator used to supply and monitor the current

the bottom side of the welds. The average values with standard deviation are presented in this paper.

\subsection{Mechanical property testing}

To analyse the mechanical properties of the weld joints, microhardness and shear tensile tests were performed. Microhardness test was done by using standard Vickers microhardness test with Struers DuraScan 70 machine with $0.1 \mathrm{~kg}$ loading. Figure 3 shows an illustrative scheme that was used to obtain the cross-section hardness profile of welds obtained at 1000 and $4500 \mathrm{rpm}$. The hardness measurements data at WFI of stir zone is presented as a chart. The tests were repeated three times, and standard deviation was calculated. Furthermore, the results were presented as a plot showing the change of hardness through all zones (base material, heat affected zone, thermomechanically affected zone, and stir zone). Both tests were performed according to relevant standards [17].

A Hegewald \& Peschke Inspect Retrofit universal tensile testing machine with a maximal load of $20 \mathrm{kN}$ was used to test tensile shear specimens. Testing speed was set to be $10 \mathrm{~mm} / \mathrm{min}$, and measurements were performed according to the relevant standards [18]. The specimens were prepared as shown in Fig. 4. The standard setup was slightly modified to engulf all three WFI. For every test, three samples were used and standard deviation was calculated.

\subsubsection{Results and discussions}

\subsection{Macro- and microstructure analysis of the weld zone}

Figure $5 \mathrm{a}$ and $\mathrm{b}$ show cross-sections of etched macrographs obtained at rotational speeds 1000 and $4500 \mathrm{rpm}$, respectively. In the two presented macrographs, a difference in the taper angle of stir zones can be observed. The increase of taper angle from $47^{\circ}$ in sample welded at $1000 \mathrm{rpm}$ to $73^{\circ}$ in sample welded at $4500 \mathrm{rpm}$ was quite prominent. This event is related to the material's increasing resistance [19]. Sample welded at $1000 \mathrm{rpm}$ possess high viscosity due to a strain-hardening effect as explained earlier $[15,19]$. This phenomenon causes stress to be oriented towards the bottom and a less conical shape of the stir zone. This way the size of the effectively welded area in all three weld faying interfaces remains similar (see Fig. 6). However, in sample welded at $4500 \mathrm{rpm}$, local thermal softening causes a high drop in the viscosity which pushes the material upwards, towards the tool periphery, and causes reduced pressure in the III WFI. Therefore, a high deviation of effective welded surfaces by weld faying interfaces can be seen. Namely, the I WFI has effective welded surfaces approximately three times smaller compared to III WFI, which can be also observed from Fig. $5 b$.

The strain hardening effect in the sample welded at $1000 \mathrm{rpm}$ causes the grain refinement (Fig. 5c) compared to the thermal softened sample welded at $4500 \mathrm{rpm}$ (Fig. 5c) and base material (Fig. 5c). The influence of all
Fig. 3 Schematic of microhardness testing performed on weld samples

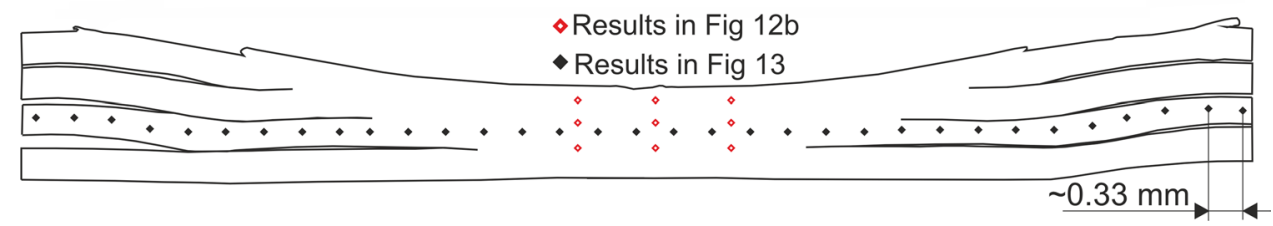




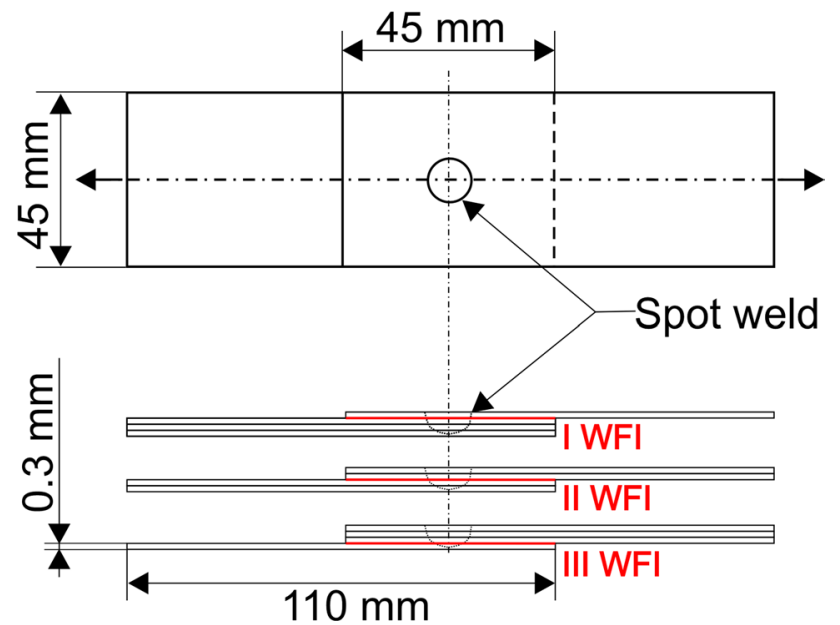

Fig. 4 Schematic of the lap tensile shear test specimens

aforementioned effects on mechanical properties will be discussed in a later section.

To fully understand the influence of rotational speed on WFI characteristics, transmission electron microscope (TEM) was used. The TEM lamella was cut from II WFI in both samples at the same place as shown in Fig. 7a. The lamellae were cut at the beginning of the stir zone because in the middle of the stir zone, there is a large scattering of
WFI due to the convex shape of the tool. In Fig. $7 \mathrm{~b}$ and c, the TEM lamellae prepared from samples welded at 1000 and $4500 \mathrm{rpm}$, respectively, are shown. Samples welded at $1000 \mathrm{rpm}$ showed a wider and more complex WFI. The measured thickness of WFI in the samples welded at $1000 \mathrm{rpm}$ was $2.19 \pm 0.21 \mu \mathrm{m}$. The WFI was found to be composed of an oxide layer in the middle (dashed blue line in Fig. 7a) which is $0.22 \pm 0.08 \mu \mathrm{m}$ thick and complex zone surrounding oxide layer composed of globular and needlelike precipitates $\mathrm{Al}_{2} \mathrm{Mg}_{3}$ (Fig. 8a and b). Furthermore, it can be noticed that the grains in WFI of welds obtained at $1000 \mathrm{rpm}$ were fibrous and significantly smaller compared to recrystallised stir zone (RSZ) which surrounds WFI. This shape and size of the grains can be a consequence of cyclic microplastic deformation of the protrusions from the rough sheet surface before the welding [10]. This can be explained by the so-called dislocation-glide-assisted-subgrain-rotation model proposed by Jata et al. [20]. In presence of high-level deformation, dislocation glide gives rise to a gradual relative rotation of adjacent subgrains. As such, the shear stress in the FSSW process is dominated by the grains, and subgrains are rotated and elongated in direction of shear load.

In the samples welded at $4500 \mathrm{rpm}$, the WFI was composed of only an oxide layer $0.54 \pm 0.21 \mu \mathrm{m}$ thick (Fig. $8 \mathrm{c}$ and d). This oxide layer was, however, thicker and more compact than that obtained from samples welded at
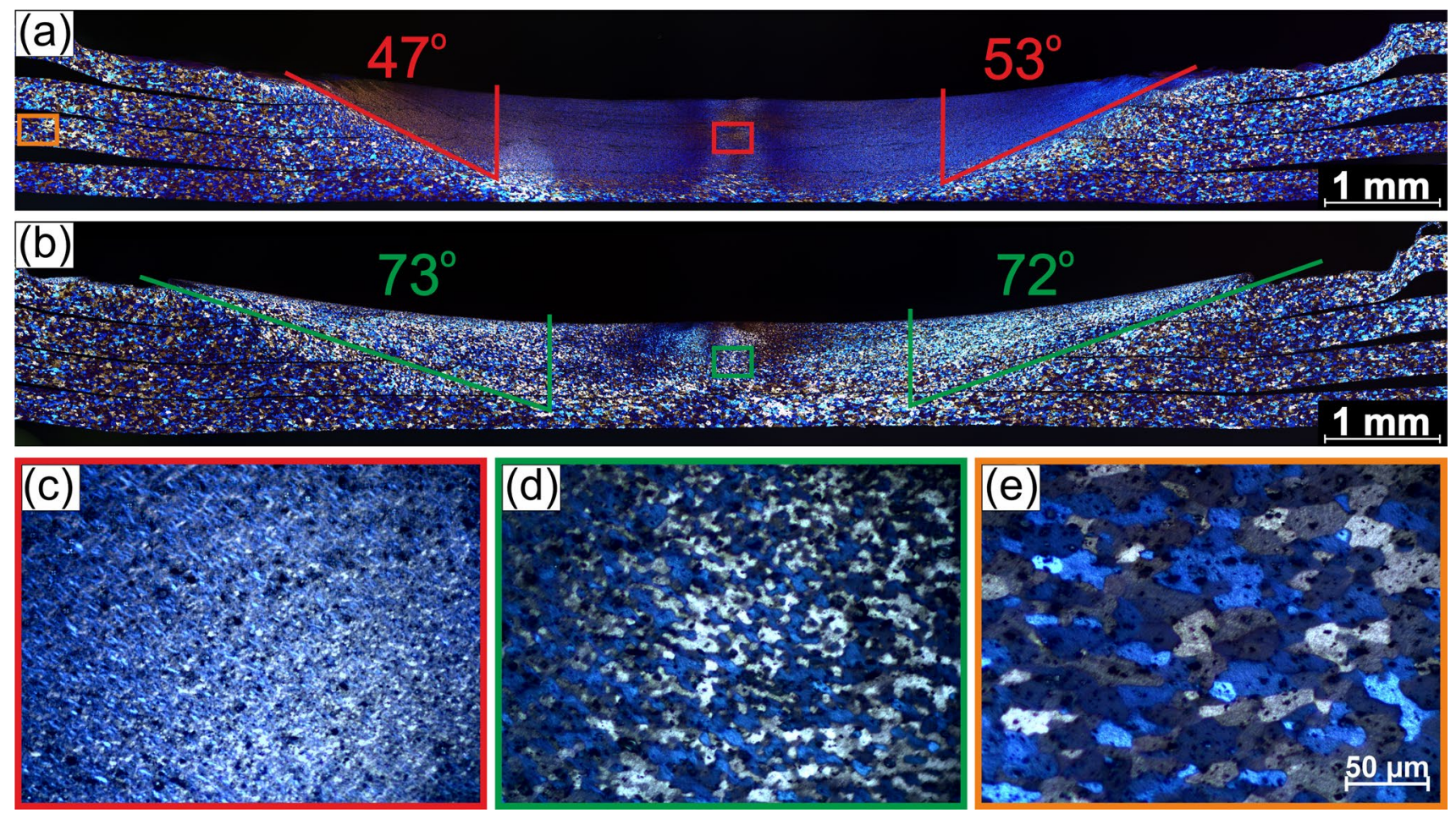

Fig. 5 Macrographs of a cross-sectional view of samples welded at a $1000 \mathrm{rpm}$ and $\mathbf{b} 4500 \mathrm{rpm}$ and micrographs of samples: $\mathbf{c}$ welded at $1000 \mathrm{rpm}$; d welded at $4500 \mathrm{rpm}$, and e base material (adapted from [10]) 


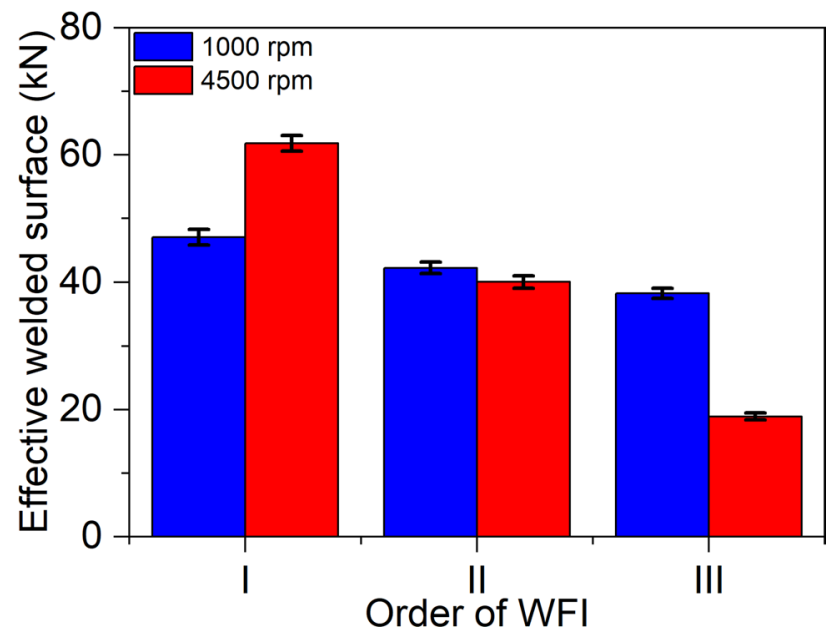

Fig. 6 Changes in the effective welded surface in different weld faying interfaces in samples welded at 1000 and $4500 \mathrm{rpm}$

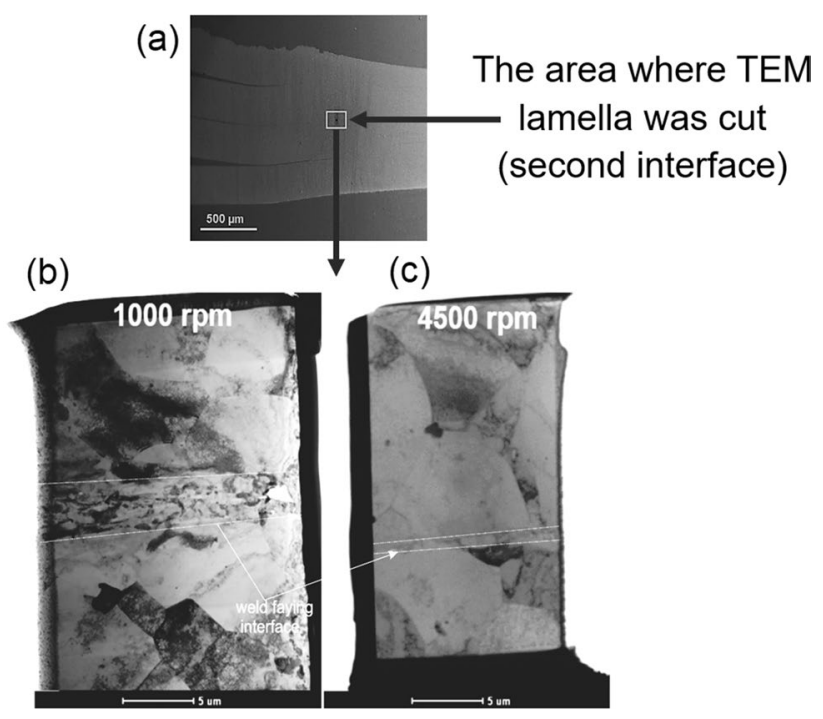

Fig. 7 a Area where TEM lamellae were cut from WFI II [10]; TEM samples of welded specimens processed at b $1000 \mathrm{rpm}$ and $\mathbf{c}$ $4500 \mathrm{rpm}$

$1000 \mathrm{rpm}$. Furthermore, there were larger pits than those in the WFI of samples obtained at $1000 \mathrm{rpm}$. It seems that the WFI of the sample welded at $4500 \mathrm{rpm}$, due to a lack of stress transferred to lower interfaces, was not stretched as the II WFI of the sample welded at $1000 \mathrm{rpm}$. Therefore, the oxide layer did not allow diffusion to occur between fragmented oxide particles. This effect was also observed by Sato et al. [11] during friction stir welding of aluminium AA 1050. The entrapped oxide layer affected the mechanical properties of the welds. However, it was observed that only root bend properties of weld were affected where the oxide layer was continuous. No effect of the oxide layer was found in the middle where the oxide layer was fragmented.

The chemical composition of the precipitates and oxide layer was determined by using energy-dispersive X-ray spectroscopy (EDX analysis), and the spatial distribution of the elements can be seen from Fig. 9 for the sample welded at $1000 \mathrm{rpm}$ and in Fig. 10 for the sample welded at $4500 \mathrm{rpm}$. This analysis revealed that the oxide layer is composed of magnesium and oxygen. It indicated that in aluminium alloy AA 5754 with $3 \%$ of magnesium, $\mathrm{Al}_{2} \mathrm{O}_{3}$, on the surface layer of the alloy, reacts with magnesium during the FSSW process to form $\mathrm{MgO}$ [10]. This phenomenon was first identified by Shirzadi et al. [21] during solid-state diffusion bonding. They noted that when aluminium alloy contains active elements such as $\mathrm{Mg}$, amorphous $\mathrm{Al}_{2} \mathrm{O}_{3}$ reacts with active elements and creates crystalline $\mathrm{MgO}$. Needlelike intermetallics are also visible in elemental mapping in Fig. 9. Those intermetallics were composed of magnesium and aluminium. On the other hand, Fig. 10 shows another observation of the intermetallics composed of aluminium, iron, and manganese. According to Choi et al. [22], those are $\mathrm{Al}_{6}(\mathrm{FeMn})$ and $\mathrm{Al}_{3} \mathrm{Mg}_{2}$ intermetallics, typical for $5 \mathrm{xxx}$ alloy. It was observed that the WFI obtained at a low rpm of 1000 contained a much larger volume of those intermetallics. According to Labus Zlatanovic et al. [10], a high local microplastic deformation caused dynamical precipitation responsible for a higher volume of intermetallics in WFI. According to D'Urso et al. [23], an increase in the rotational speed increases the local temperature which in turn leads to thermal softening of WFI (such as in the case of $4500 \mathrm{rpm}$ ) leading to a lower viscosity and dynamic recovery as also confirmed by Soare et al. [24].

\subsection{Electrical resistance}

According to Raeisinia et al. [25], the value of electrical resistivity is dependent on various microstructural parameters. The difference in specific electrical resistance of the base material and samples welded at 1000 and $4500 \mathrm{rpm}$ is presented in Fig. 11.

The samples welded at $1000 \mathrm{rpm}$ showed higher specific electrical resistance, followed by the sample welded at $4500 \mathrm{rpm}$. The lowest specific resistance was for the base material. This effect can be correlated with two microstructural observations. In the samples welded at $1000 \mathrm{rpm}$, strain hardening is predominant, and this causes the accumulation of dislocations. Raeisinia et al. [25] investigated the influence of dislocation on the electrical resistance of AA 5754 alloy. They found that an increase in dislocation density causes an increase in the specific resistance. Furthermore, Lee et al. [26] investigated the influence of the intermetallic compound layer thickness on the electrical and mechanical properties of $\mathrm{Cu} / \mathrm{Al}$ joint 
Fig. 8 TEM micrograph of WFI: a bright field of sample welded at $1000 \mathrm{rpm}$ (lower magnification) [10]; b highangle annular dark-field image of sample welded at $1000 \mathrm{rpm}$ (higher magnification); c bright field of sample welded at $4500 \mathrm{rpm}$ (lower magnification); d high-angle annular dark-field image of sample welded at $4500 \mathrm{rpm}$ (higher magnification)
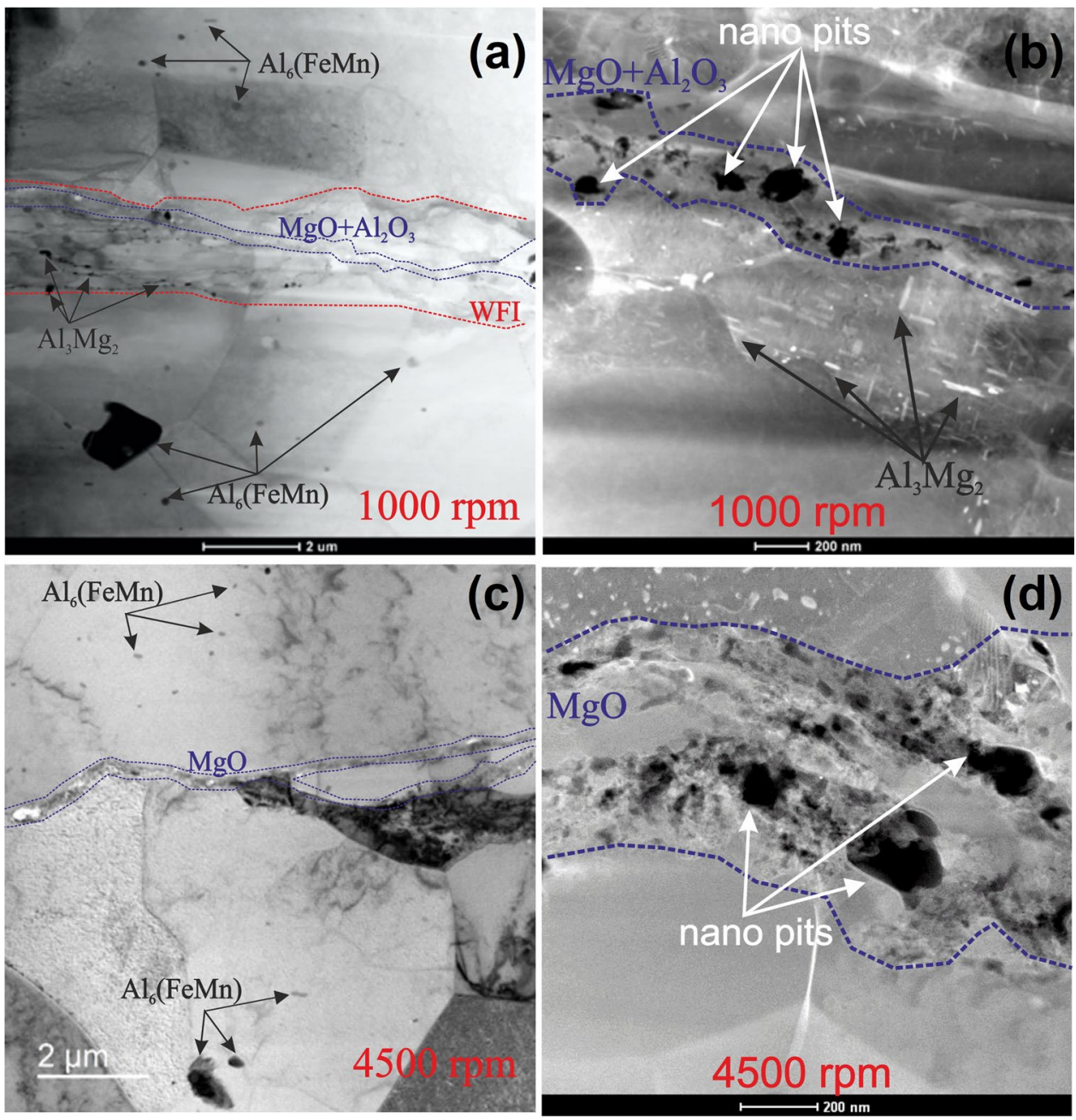
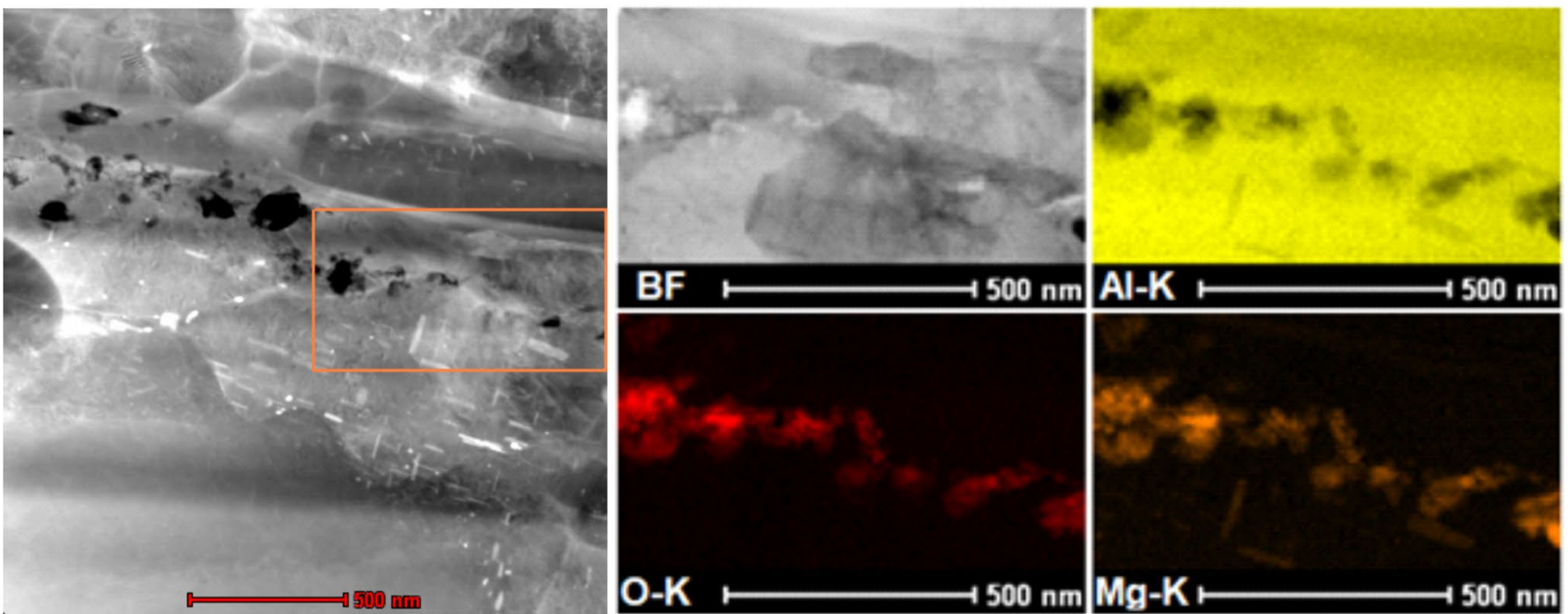

Fig. 9 High-angle annular dark-field scanning transmission electron microscope (HAADF-STEM) image of the WFI in sample welded at $1000 \mathrm{rpm}$ with corresponding energy-dispersive X-ray spectroscopy (STEM/EDX) elemental mappings of the area marked with an orange square 

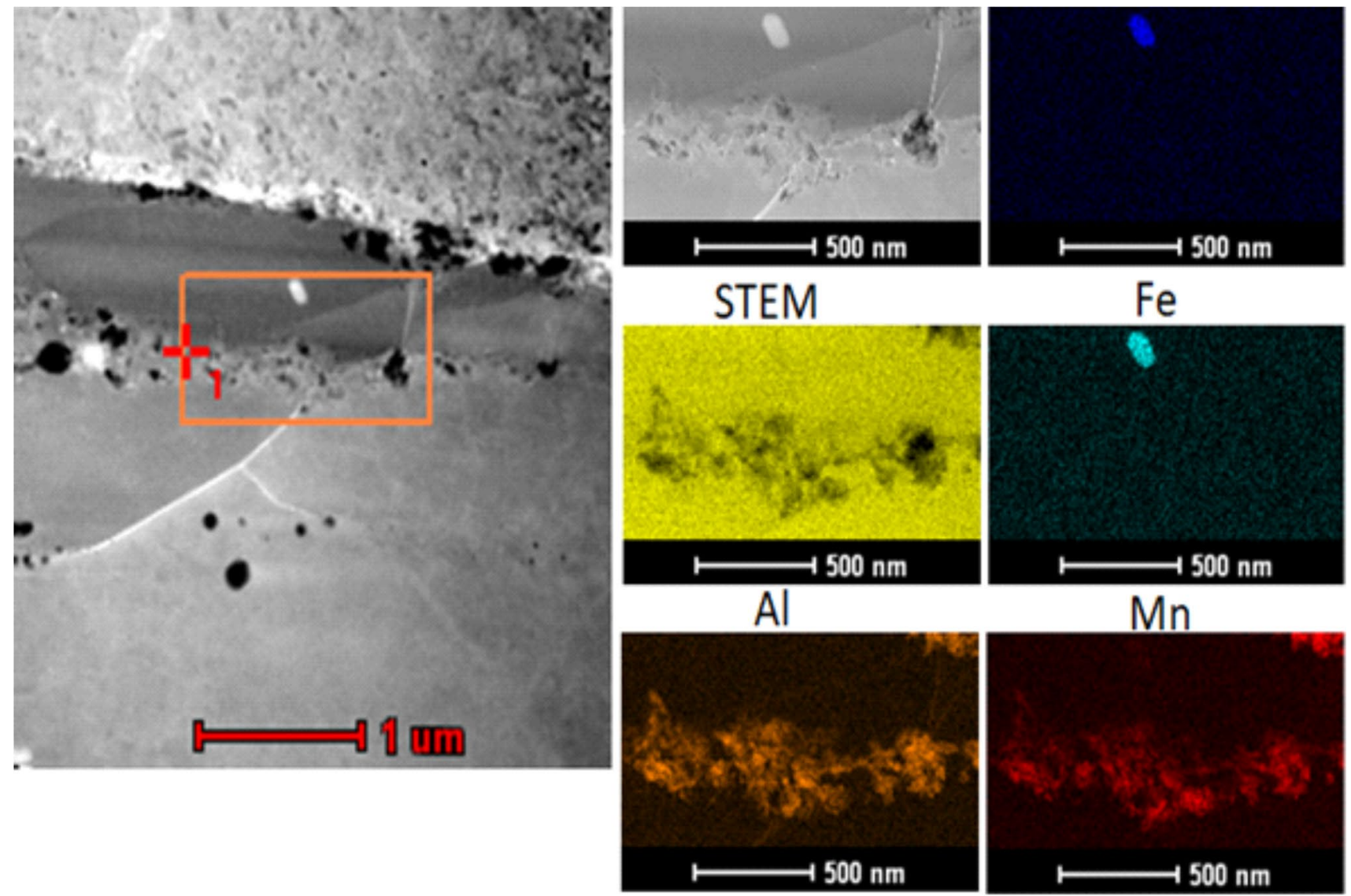

$\mathrm{Mg}$

Fig. 10 High-angle annular dark-field scanning transmission electron microscope (HAADF-STEM) image of the WFI in sample welded at $4500 \mathrm{rpm}$ with corresponding energy-dispersive X-ray spectroscopy (STEM/EDX) elemental mappings of the area marked with an orange square

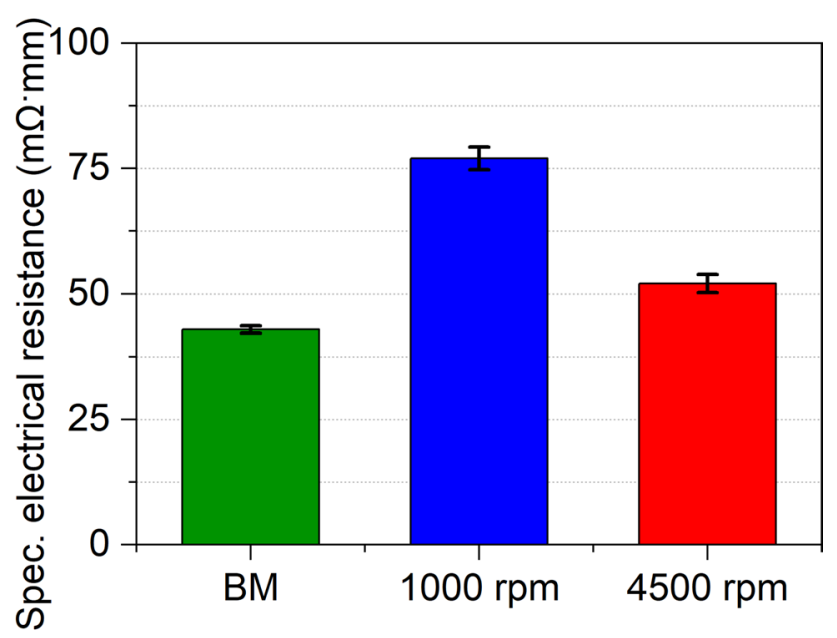

Fig. 11 Specific electrical resistance measured for the base material and the samples welded at 1000 and $4500 \mathrm{rpm}$ during annealing. The influence of intermetallic on the electrical properties was high. It was found that the thicker intermetallic layer degraded the electrical resistance. Furthermore, Mubiayi et al. [27] investigated the influence of rotational speed at electrical resistivity during FSSW of $\mathrm{Al} / \mathrm{Cu}$ dissimilar alloys. An increase in rotational speed caused a decrease in the electrical resistance. Also, the resistance of welds was higher compared to that of the base material, which was correlated with a higher number of intermetallics present in the weld.

In the samples welded at $1000 \mathrm{rpm}$, there were three WFI regions with a higher amount of intermetallics. Furthermore, there is also an oxide layer in the middle of every WFI with a very high electrical resistance of about $10^{16} \Omega \cdot \mathrm{m}$ [28] combined with nano pits. All those parameters combined will influence the electrical resistance of the weld, and this influence in weld obtained at $1000 \mathrm{rpm}$ compared to the base material was estimated to be as much as $42 \%$ during this investigation. In the samples welded at $4500 \mathrm{rpm}$, the influence was lower (14\%) which can be correlated with the fact that only three thicker oxide layers were present in the 
stir zone at the weld interface and no additional intermetallics were found.

\subsection{Mechanical properties}

To understand the influence of size and composition of WFI on weld properties, shear-tensile and microhardness tests were done. The shear-tensile properties and microhardness of all three WFI are shown in Fig. 12.

It was observed that the rotational speed during FSSW influences the mechanical properties in two ways:

(i) Thermal softening of stir zone in the samples welded at $4500 \mathrm{rpm}$ causes shear failure load to reduce (Fig. 12a) and microhardness to drop below the values of base material (Fig. 13). Also, the strain hardening of the stir zone in the samples welded at $1000 \mathrm{rpm}$ significantly improves the mechanical properties of the weld (see Fig. 13) which reveals the microhardness profile at the cross-section of the weld.

(ii) The rotational speed also influences the size of the effective welded surface. The difference in the size of the effective welded surface is most pronounced in I and III WFI, while II WFI in both samples (welded at 1000 and $4500 \mathrm{rpm}$ ) are approximately the same. However, even the size of effective welded surface in I WFI for sample welded at $4500 \mathrm{rpm}$ is significantly higher compared to that of $1000 \mathrm{rpm}$ (Fig. 6), the shear failure load was almost the same (Fig. 12a). This was caused by higher mechanical properties of the strain hardened stir zone of the weld obtained at $1000 \mathrm{rpm}$ compared to the thermal softened stir zone of the sample welded at 4500 rpm (Fig. 12b).

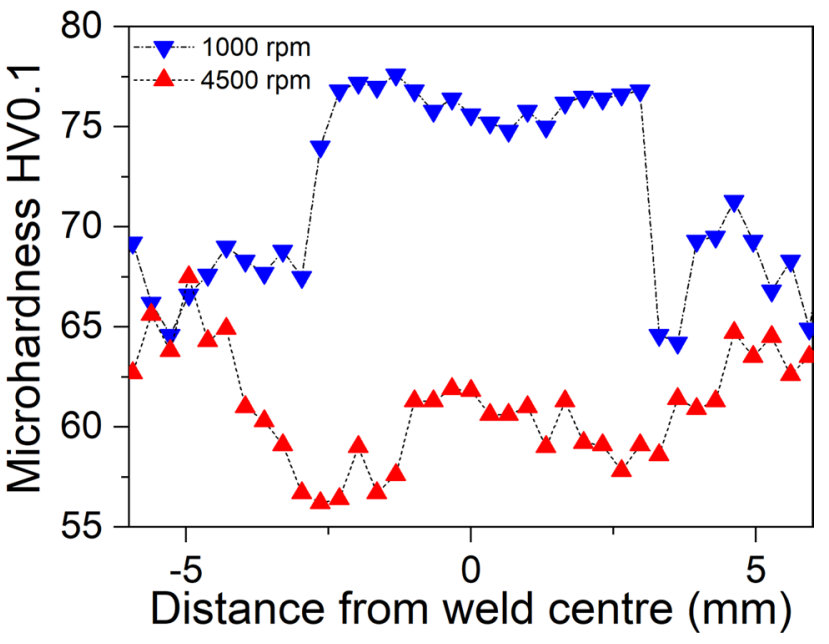

Fig. 13 Microhardness profile of the cross-section of samples welded at 1000 and $4500 \mathrm{rpm}$ obtained in all specific zones (base material, heat affected zone, thermomechanically affected zone, and stir zone)

Furthermore, the effective welded surface of the I WFI is larger than that of II WFI, but the shear failure load is higher in II WFI. The significant thinning of the first sheet due to penetration of the tool was responsible for the drop of the shear failure load in I WFI. The size of the III WFI was the smallest of all three WFI (Fig. 6), which caused the shear load to be the lowest. Also, since, III WFI in the sample welded at $1000 \mathrm{rpm}$ had a larger effective welded surface (Fig. 6) and higher microhardness (Fig. 12b), the shear failure load in this case was also higher.

Figure 14 shows the evolution of tensile shear load versus the displacement. The samples welded at $1000 \mathrm{rpm}$ showed
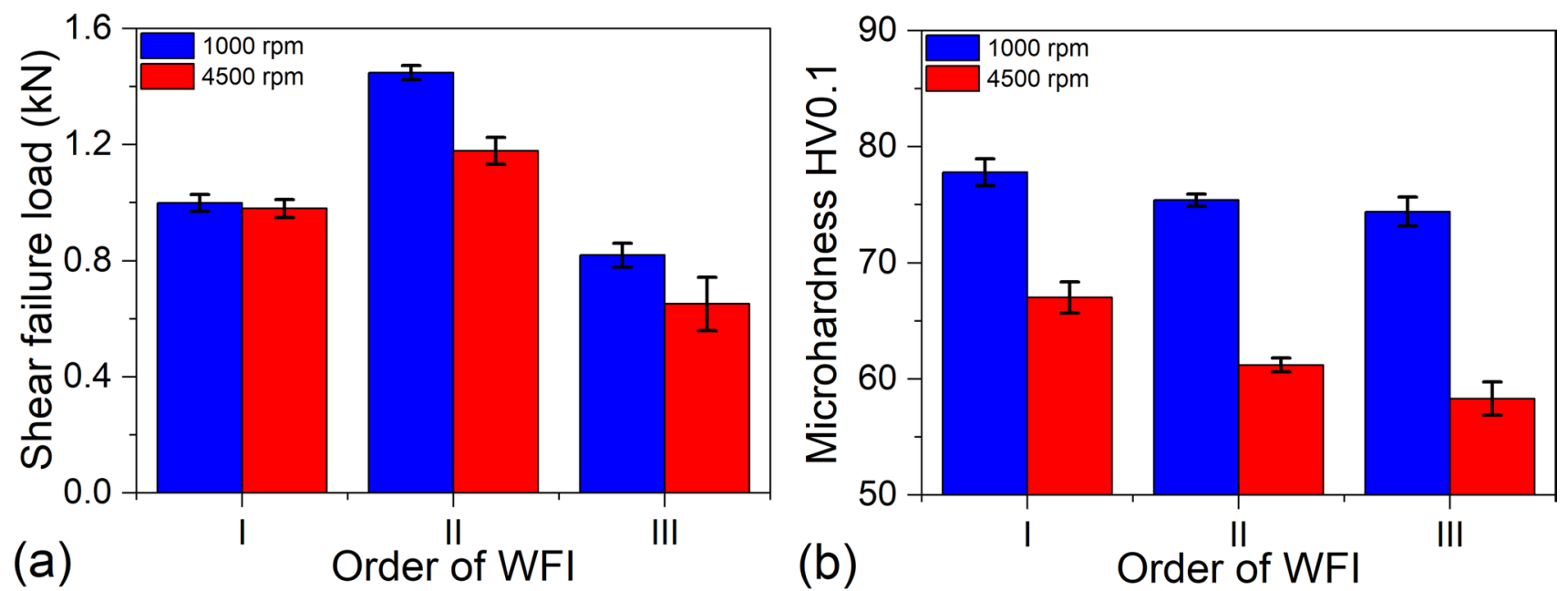

Fig. 12 Influence of rotational speed and order of WFI on the a shear failure load; $\mathbf{b}$ microhardness measured in the middle of the stir zone as shown in Fig. 3 

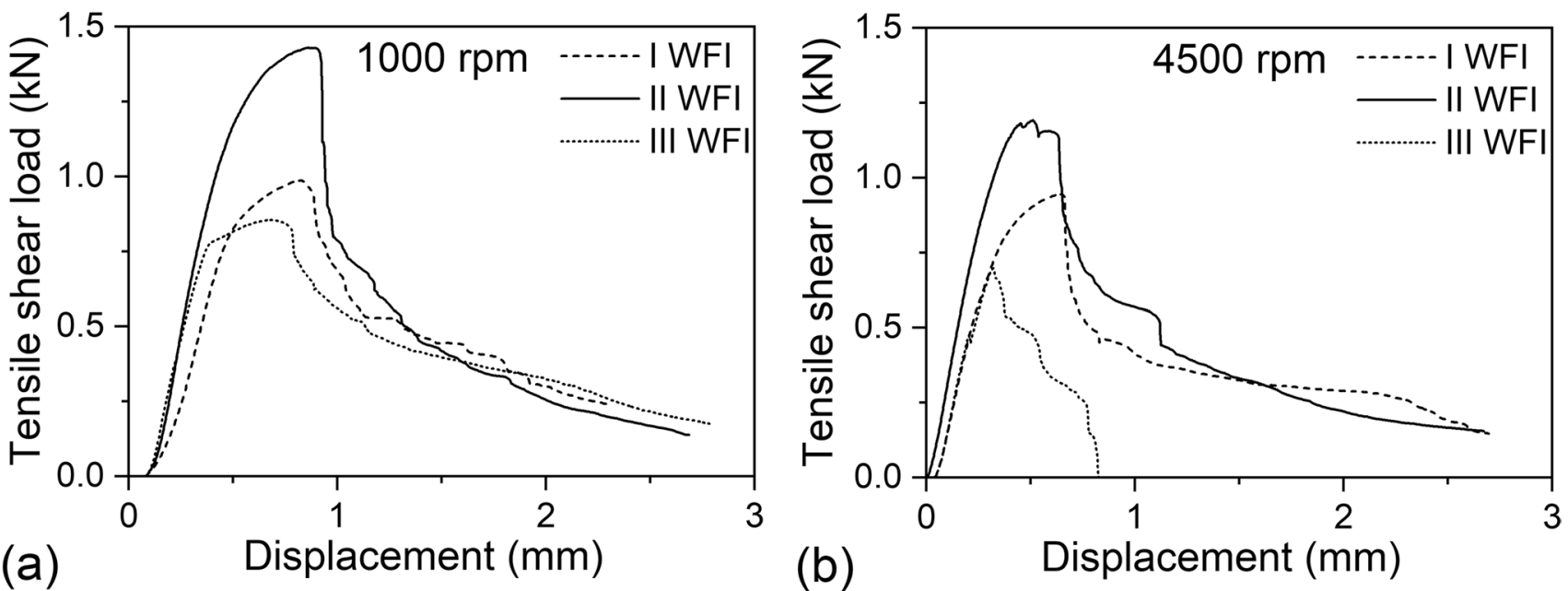

Fig. 14 Failure behaviour of the joints welded at a $1000 \mathrm{rpm}$; b $4500 \mathrm{rpm}$

a higher tensile shear load capacity for the II and III WFI, while the tensile shear load for the I WFI was almost the same. In the samples welded at $1000 \mathrm{rpm}$, the values of the tensile shear load between I and III layers were similar compared to the samples welded at $4500 \mathrm{rpm}$, where a high difference in tensile shear load and elongation was observed. This effect can be explained by the observation made by Labus Zlatanovic et al. [19] that samples welded at higher rotational speed (4000 rpm) under similar conditions revealed a number of delamination circles in the III WFI. Those delamination circles are a consequence of low stress transferred to the bottom of the weld zone due to low viscosity. Most material tends to go upwards which is why the I WFI in the sample welded at $4500 \mathrm{rpm}$ has a higher effective welded surface and III WFI has the smallest one (Fig. 6). The II WFI in the samples welded at $4500 \mathrm{rpm}$ showed unstable behaviour near the shear fracture load, which can also be a consequence of a number of micro and nano pits found in the II WFI during the TEM investigation (shown earlier in Fig. 8). Even when there were also some pits found in the sample welded at $1000 \mathrm{rpm}$, the samples welded at low rpm did not rupture in the middle of the WFI [10], due to a high microstrain hardening of the WFI (small grains and high volume of dislocation). Instead, the rupture occurs on the border between WFI and recrystallised stir zone, on intermetallics $\mathrm{Al}_{2} \mathrm{Mg}_{3}$ which seeds the nucleation for rupture.

\section{Conclusions}

Friction stir spot welding (FSSW) has the potential to become a technology suitable for welding battery components, standard-thermal connectors, and terminals. However, one of the biggest challenges posed by this technology is to provide quality weld joints with low electrical resistance, which is an important requirement of the electrical industry. In this paper, a brief presentation of the influence of rotational speed at microstructure, electrical and mechanical properties was analysed, and the following conclusions can be summarised:

(I) The stir zone was found to differ for different rotational speeds. At $1000 \mathrm{rpm}$ where strain hardening dominates compared to $4500 \mathrm{rpm}$ where thermal softening prevails, weld shape showed an identifiable difference. Also, the size of the weld faying interfaces (WFI) within one sample showed differences. For instance, the samples welded at $1000 \mathrm{rpm}$ had a low difference between all three WFI, while the samples welded at $4500 \mathrm{rpm}$ showed the III WFI to be $69 \%$ smaller than the I WFI. In samples welded at $1000 \mathrm{rpm}$, the III WFI was seen to be smaller than that of the I WFI by about $19 \%$. Also, the composition of WFI differs between those two samples. The samples welded at $1000 \mathrm{rpm}$ revealed complex WFI with oxide layer and pits in the middle and microstrain hardened zone surrounding the oxide layer with a higher volume of precipitation. On the other hand, the samples welded at $4500 \mathrm{rpm}$ had only a thicker oxide layer with several micro and nano pits.

(II) It was noted that the electrical resistance of the weld joints depends significantly on the rotational speed. Although the electrical resistance of the welded joints (regardless of the rotational speed) was seen to be higher in all cases compared to the base material, but with respect to the base material, 
it increases by about $42 \%$ for low rotation speed and by about $14 \%$ for the higher rotation speed.

(III) Shear strength and microhardness were higher for the samples welded at $1000 \mathrm{rpm}$. The II WFI showed the highest shear strength in both samples, while III WFI showed the lowest. Microhardness was highest for the I WFI and lowest for the III WFI. In samples welded at $1000 \mathrm{rpm}$, microhardness increased significantly due to strain hardening, whereas in samples welded at $4500 \mathrm{rpm}$, the microhardness of the stir zone decreases below the base material due to a prevalent thermal softening mechanism.

\begin{abstract}
Acknowledgements All authors greatly acknowledge the financial support provided by the UKRI via Grants No. EP/L016567/1, EP/ S013652/1, EP/S036180/1, EP/T001100/1 and EP/T024607/1, Transforming the Foundation Industries NetworkPlus Feasibility study award to LSBU (EP/V026402/1), the Royal Academy of Engineering via Grants No. IAPP18-19\295 and TSP1332, EURAMET EMPIR A185 (2018), the EU Cost Action (CA15102, CA18125, CA18224 and CA16235), The Hubert Curien Partnership award 2022 from the British Council and the Newton Fellowship award from the Royal Society (NIF\R1\191571). Wherever applicable, the work made use of Isambard Bristol, UK, supercomputing service accessed by a Resource Allocation Panel (RAP) grant as well as ARCHER resources (Project e648).
\end{abstract}

Funding Open Access funding enabled and organized by Projekt DEAL. The authors are grateful to the DAAD program for financial support to perform the experimental work. Specific thanks to the Royce PhD Equipment Access Scheme enabling access to TEM facilities at Royce@Cambridge via UKRI Grant EP/R00661X/1 and to the STSM support from Cost Action CA15102 (funded by H2020). Also, this paper has been supported by the Ministry of Education, Science and Technological Development through project no. 451-03-68/2020 14/200156: "Innovative scientific and artistic research from the FTS activity domain."

Availability of data and material The reported in this paper can be obtained from the Cranfield repository (https://doi.org/10.17862/cranf ield.rd.15164166).

Code availability Not applicable.

\section{Declarations}

Ethics approval Not applicable.

Consent to participate Not applicable.

Consent for publication All authors permit the publisher to publish the work.

Open Access This article is licensed under a Creative Commons Attribution 4.0 International License, which permits use, sharing, adaptation, distribution and reproduction in any medium or format, as long as you give appropriate credit to the original author(s) and the source, provide a link to the Creative Commons licence, and indicate if changes were made. The images or other third party material in this article are included in the article's Creative Commons licence, unless indicated otherwise in a credit line to the material. If material is not included in the article's Creative Commons licence and your intended use is not permitted by statutory regulation or exceeds the permitted use, you will need to obtain permission directly from the copyright holder. To view a copy of this licence, visit http://creativecommons.org/licenses/by/4.0/.

\section{References}

1. Ojo OO, Taban E, Kaluc E (2015) Friction stir spot welding of aluminum alloys: a recent review. Mater Test 57:595-627. https:// doi.org/10.3139/120.110752

2. Shen Z, Yang X, Yang S, Zhang Z, Yin Y (2014) Microstructure and mechanical properties of friction spot welded 6061-T4 aluminum alloy. Mater Des 54:766-778. https://doi.org/10.1016/j. matdes.2013.08.021

3. Heidarzadeh A, Mironov S, Kaibyshev R, Çam G, Simar A, Gerlich A, Khodabakhshi F, Mostafaei A, Field DP, Robson JD, Deschamps A, Withers PJ (2020) Friction stir welding/ processing of metals and alloys: a comprehensive review on microstructural evolution. Prog Mater Sci 100752. https://doi. org/10.1016/j.pmatsci.2020.100752

4. Cooper DR, Allwood JM (2014) Influence of diffusion mechanisms in aluminium solid-state welding processes. Procedia Eng 81:2147-2152. https://doi.org/10.1016/j.proeng.2014.10.300

5. Sun Y, Morisada Y, Fujii H, Tsuji N (2018) Ultrafine grained structure and improved mechanical properties of low temperature friction stir spot welded 6061-T6 Al alloys. Mater Charact 135:124-133. https://doi.org/10.1016/j.matchar.2017.11.033

6. Atak A, Ş1k A, Özdemir V (2018) Thermo-mechanical modeling of friction stir spot welding and numerical solution with the finite element method. Int J Eng Appl Sci 5:70-75

7. Chiou YC, Te LC, Lee RT (2013) A pinless embedded tool used in FSSW and FSW of aluminum alloy. J Mater Process Technol 213:1818-1824. https://doi.org/10.1016/j.jmatprotec.2013.04. 018

8. Bakavos D, Prangnell PB (2009) Effect of reduced or zero pin length and anvil insulation on friction stir spot welding thin gauge 6111 automotive sheet. Sci Technol Weld Join 14:443-456. https://doi.org/10.1179/136217109X427494

9. Bakavos D, Chen Y, Babout L, Prangnell P (2011) Material interactions in a novel pinless tool approach to friction stir spot welding thin aluminum sheet. Metall Mater Trans A Phys Metall Mater Sci 42:1266-1282. https://doi.org/10.1007/s11661-010-0514-x

10. Zlatanovic DL, Balos S, Bergmann JP, Rasche S, Zavašnik J, Panchal V, Sidjanin L, Goel S (2021) In-depth microscopic characterisation of the weld faying interface revealing stress-induced metallurgical transformations during friction stir spot welding. Int J Mach Tools Manuf 103716. https://doi.org/10.1016/j.ijmac htools.2021.103716

11. Sato YS, Takauchi H, Park SHC, Kokawa H (2005) Characteristics of the kissing-bond in friction stir welded Al alloy 1050. Mater Sci Eng A 405:333-338. https://doi.org/10.1016/j.msea.2005.06. 008

12. Sarkar R, Pal TK, Shome M (2016) Material flow and intermixing during friction stir spot welding of steel. J Mater Process Technol 227:96-109. https://doi.org/10.1016/j.jmatprotec.2015.08.006

13. Tier MD, Rosendo TS, Dos Santos JF, Huber N, Mazzaferro JA, Mazzaferro CP, Strohaecker TR (2013) The influence of refill FSSW parameters on the microstructure and shear strength of 5042 aluminium welds. J Mater Process Technol 213:997-1005. https://doi.org/10.1016/j.jmatprotec.2012.12.009 
14. Li G, Zhou L, Luo L, Wu X, Guo N (2019) Microstructural evolution and mechanical properties of refill friction stir spot welded alclad 2A12-T4 aluminum alloy. J Mater Res Technol 8:41154129. https://doi.org/10.1016/j.jmrt.2019.07.021

15. Labus Zlatanovic D, Balos S, Bergmann JP, Köhler T, Grätzel M, Sidjanin L, Goel S (2020) An experimental study on lap joining of multiple sheets of aluminium alloy ( AA 5754) using friction stir spot welding. Int J Adv Manuf Technol 107:3093-30107. https:// doi.org/10.1007/s00170-020-05214-z

16. Lerner L (1996) Physics for Scientist and Engineers, Volume 2. Jones and Bartlett Publishers

17. (2018) BS EN ISO 6507-1 2018 Vickers hardness test- Part 1. $1-30$

18. (2016) DIN EN ISO 14273 Resistance welding - destructive testing of welds - specimen dimensions and procedure for tensile shear testing resistance spot and embossed projection welds. 1-14

19. Labus Zlatanovic D, Baloš S, Bergmann JP, Rasche S, Pecanac M, Goel S (2021) Influence of tool geometry and process parameters on friction stir welded aluminium alloy Aa6082-T6 - an experimental investigation. Materials (Basel) 14. https://doi.org/ 10.3390/ma14051157

20. Jata KV, Semiatin SL (2000) Continuous dynamic recrystallization during friction stir welding of high strength aluminum alloys. Scr Mater 43:743-749. https://doi.org/10.1016/S1359-6462(00) 00480-2

21. Shirzadi AA, Assadi H, Wallach ER (2001) Interface evolution and bond strength when diffusion bonding materials with stable oxide films. Surf Interface Anal 31:609-618. https://doi.org/10. 1002/sia.1088

22. Choi DH, Ahn BW, Quesnel DJ, Jung SB (2013) Behavior of $\beta$ phase $(\mathrm{A} 13 \mathrm{Mg} 2)$ in AA 5083 during friction stir welding. Intermetallics 35:120-127. https://doi.org/10.1016/j.intermet.2012.12. 004
23. D'Urso G, Giardini C (2016) Thermo-mechanical characterization of friction stir spot welded AA7050 sheets by means of experimental and FEM analyses. Materials (Basel) 9:1-14. https://doi. org/10.3390/ma9080689

24. Soare MA, Curtin WA (2008) Solute strengthening of both mobile and forest dislocations: The origin of dynamic strain aging in $\mathrm{fcc}$ metals. Acta Mater 56:4046-4061. https://doi.org/10.1016/j.actam at.2008.04.027

25. Raeisinia B, Poole WJ (2006) Electrical resistivity measurements : a sensitive tool for studying aluminum alloys. Mater Sci Forum 519-521:1391-1396. https://doi.org/10.4028/www.scientific.net/ MSF.519-521.1391

26. Lee W, Bang K, Jung S (2005) Effects of intermetallic compound on the electrical and mechanical properties of friction welded $\mathrm{Cu}$ / Al bimetallic joints during annealing. J Alloys Compd 390:212219. https://doi.org/10.1016/j.jallcom.2004.07.057

27. Mubiayi MP, Akinlabi ET, Makhatha ME (2017) Microstructure and electrical resistivity properties of copper and aluminium friction stir spot welds. Proc 2017 8th Int Conf Mech Intell Manuf Technol ICMIMT 2017 42-47. https://doi.org/10.1109/ICMIMT. 2017.7917432

28. Hornak J, Trnka P, Kadlec P (2018) Magnesium oxide nanoparticles : dielectric properties, surface functionalization and improvement of epoxy-based composites insulating properties. Nanomaterials 8:1-17. https://doi.org/10.3390/nano8060381

Publisher's Note Springer Nature remains neutral with regard to jurisdictional claims in published maps and institutional affiliations. 